SILVA, Mariza Vieira da. História da

Alfabetização no Brasil: sentidos e sujeitos da escolarização. Campinas, SP:

Editora da Unicamp, 2015. 432p.

\title{
O DIREITO À DIFERENÇA EM UM MUNDO FEITO EM ALFABETO
}

\section{CIDARLEY GRECCO FERNANDES COELHO ${ }^{1}$}

\author{
Programa de Pós-Graduação em Linguística \\ Instituto de Estudos da Linguagem - Universidade Estadual de Campinas \\ Rua Sérgio Buarque de Holanda, 571 - 13083-859 - Campinas - SP - Brasil \\ profacidagrecco@gmail.com
}

Num momento em que discursos sobre a educação no Brasil - que ressaltam aspectos como a necessidade de repensar o modelo educacional vigente; as políticas públicas por uma escola de qualidade; os limites e possibilidades diante do fracasso escolar; os questionamentos a respeito da laicidade e suposta neutralidade políticoreligiosa - se multiplicam e reverberam reclamando sentidos, a publicação de História da Alfabetização: sentidos e sujeito da escolarização, de Mariza Vieira da Silva, mais do que nos fazer pensar sobre esses sentidos que nos expõem aos ditos e não-ditos, ao que é silenciado e ao que é já-dito historicamente sobre educação, sobre a alfabetização, sobre a escola de ensinar a ler, escrever e contar. Muitos sentidos, muitos debates, muitas palavras. Educação está na ordem do dia. O que fica silenciado até aqui? O que não está dito e o que está no não-dito? Como pensar o já-dito na história, na relação com a língua e com a constituição do sujeito da escolarização no Brasil?

Além de belíssima e inaugural, como afirma Orlandi no prefácio do livro, a obra é imprescindível para todos aqueles que desejem pensar como se constitui a história e o sujeito da escolarização num país determinado pelo processo de colonização, por uma sociedade escravocrata. Uma obra que retoma, não apenas sua tese de doutorado defendida em 1998, mas quase vinte anos de trabalho em torno do tema da alfabetização/escolarização do português como língua nacional, com articulações teóricas e construção de um dispositivo de análise, "um objeto discursivo em que o simbólico e o político se articulam" (SILVA, 2015, p. 26). Obra que se apresenta como presente para nós leitores interessados em pensar sentidos possíveis para (a transformação da) educação.

Organizado em três capítulos, o livro inicia situando o leitor nas condições de produção da obra por meio do percurso histórico de trabalho da analista de discurso, na relação com seu objeto de análise, através do encontro com o referencial que constituirá

\footnotetext{
${ }^{1}$ Doutoranda em Linguística no Programa de Pós-Graduação em Linguística do Instituto de Estudos da Linguagem, Universidade Estadual de Campinas.
} 
o corpus, "um arquivo constituído de discursos sobre o Brasil, os brasileiros, a construção da língua nacional e o processo de escolarização, nos quais a oposição alfabetizadoanalfabetismo faz trabalhar as contradições presentes nessas histórias que se entrelaçam" (SILVA, 2015, p. 203). Faz efeito sobre essa reflexão todo o trabalho da pesquisadora na área educacional, desenvolvido na Educação Básica, no MEC e no INEP, em Brasília; assim como o dispositivo teórico, que é a Análise de Discurso.

Nessa primeira abordagem, Silva (2015, p. 81) já nos coloca as questões fundamentalmente norteadoras da análise: a da presença/ausência na dicotomia analfabetismo-alfabetização e analfabeto-alfabetizado, a da assimetria/discrepância presentes nos termos, bem como a da presença de um até referido a analfabeto como elemento mobilizador "de um resto fundamental, constitutivo". Ao mesmo tempo em que apresenta seu recorte discursivo que constitui o corpus de análise, explicita seu dispositivo teórico e analítico, num batimento entre descrição e interpretação, de modo que se estabeleça uma relação entre o dado, o real imaginário, o histórico-social, o psicológico, o pedagógico, o linguístico e o político, visando às contradições constitutivas dos discursos apresentados.

Sem pretensão à completude, o que seria uma negação de seu aporte teórico, a autora de História da Alfabetização expõe as obras representativas das áreas do conhecimento implicadas no processo de escolarização (e que se constituíram como fontes para as reflexões em torno da formação do brasileiro) ao seu dispositivo de análise, dando ênfase aos discursos que construíram esse processo no período colonial. Pela materialidade do discurso acadêmico-científico, Silva (2015) toma primeiro a temática da Educação nas obras de José Ricardo Pires de Almeida, História da instrução pública: 1500-1889, e Anísio Teixeira, A educação e a crise brasileira; Educação não é privilégio; Educação e o mundo moderno. A partir dessas obras mostra como se constitui o sujeito da escolarização - "o ignorante até das letras do A,B,C" (p. 60), [...] resto a ser regenerado [...] sujeito tutelado humana e moralmente, $[\ldots]$ a quem é preciso ensinar até mesmo a querer, a escolher, a desejar" (SILVA, 2015, p. 131). Além disso, a análise expõe a concepção de língua (cujo ensino vai além do saber ler e escrever a fim de moralizar, civilizar) que permeia os discursos considerando as "raízes clássicas dessa civilização", o que produz um apagamento da heterogeneidade linguística constitutiva do Brasil.

Heterogeneidade não apenas linguística, mas de toda formação do brasileiro relegada a um pano de fundo. "'No fundo do quadro' - esse é o lugar que, realmente, os escravos negros e os índios têm" (SILVA, 2015, p. 139), como mostra a análise das obras de Fernando de Azevedo: A cultura Brasileira; Introdução ao estudo da cultura no Brasil. A esse respeito, o movimento de interpretação da autora explicita de que modo a cultura dos jesuítas foi talhando as primeiras formas práticas da escola brasileira, do processo de escolarização do português como língua nacional, afirmando que, no começo, "o aluno não era ignorante, [...] apenas das letras, das artes e das ciências [...] mas, era, sim, selvagem, bárbaro, herege e infiel" e a "falta de civilização e de cultura era, antes e sobretudo, falta de fé e presença de maus costumes" (p. 150-151). Assim, a relação com a escrita no espaço de enunciação brasileiro é uma relação inaugurada pela civilização, cuja significação foi determinada por uma formação discursiva europeia-branca-cristã. 
Após a análise dessas obras, que têm seu foco na cultura, a autora passa à leitura de três importantes referências no campo da História. A primeira, Sérgio Buarque de Holanda, tomando como recorte os livros Visão do paraíso: os motivos edênicos no descobrimento e colonização do Brasil; Raízes do Brasil; História Geral da civilização brasileira, tomo I, volumes 1 e 2. A segunda, Nelson Werneck Sodré, com História da literatura brasileira: seus fundamentos econômicos; e, por fim, S.I. Serafim Leite, com a obra História da Companhia de Jesus no Brasil, tomos I e II.

Partindo da visão edênica do Novo Mundo na obra de Buarque de Holanda e dos primeiros escritores, passando pela separação que se faz nas descrições das belezas/maravilhas naturais da terra e dos sujeitos que aqui estavam, Silva (2015) questiona quem seriam os habitantes desse éden e como seria possível conciliar a visão de paraíso em contraponto com os bárbaros que habitavam essa terra. A análise aponta para um sujeito que pode entrar para a história e participar dela como objeto de conhecimento, como resto a ser regenerado, "matéria que se sujeitou mal", em oposição à cultura ibérica. Matéria feita de papel em branco, metáfora fundadora para o analfabeto, que o significa como sujeito a ser salvo e necessitado de virtudes, pois "éramos papel branco em que poucas letras bastariam e onde se poderia imprimir o que se quisesse [...] depois nos transformaríamos em ferro frio que se converte na forja" (idem, p. 167-169).

Perguntando como a contradição constitutiva da formação do brasileiro significa(ou) em nossa memória, a analista observa que as relações entre a oposição oralidade do selvagem e escrita do civilizado vão ganhando outros sentidos, numa divisão entre aquele que tem acesso e se coloca como intérprete daquele que fora excluído da escolarização, cujos efeitos podem ser observados em uma espécie de ensino verbalista, retórico, de torneios literários e de cultura livresca. O sujeito em branco só passa a ser alguma coisa pela inscrição da letra (e poucas bastam), da virtude e do conjunto de coisasa-saber: o ABC básico das virtudes mais necessárias.

Refletindo sobre a História da Literatura como parte que constitui discursos sobre cultura, a partir da obra de Sodré (1964), à autora de História da Alfabetização interessa "compreender [...] a determinação material de certos efeitos literários produzidos pela e na história da língua nacional e na de sua escolarização" (SILVA, 2015, p. 181), cujo processo nos constituiu como sujeitos da escrita por um passado que se fez linguagem, que se fez memória, sendo somente de dentro dessa memória possível se pensar em lutar para construir uma nação. No trabalho de investigação dessa memória, Mariza Vieira da Silva nos mostra pela análise primorosa dos recortes como a condição de população analfabeta, vinda de fora, da colonização, nos afetou negativamente e de que modo os colégios foram responsáveis pela formação de uma elite social, política e cultural do país, por meio do que Sodré (1964) chamou de "aliciamento natural", reforçando a divisão entre os que sabiam e os que não sabiam ler e escrever. Desse modo, ser letrado, alfabetizado, sempre foi marca de diferença.

Marca advinda de um saber como elemento de diferenciação, como "um instrumento de unidade e, ao mesmo tempo, de diferenciação" (idem, ibidem). Contudo, a autora prossegue em sua análise mostrando os deslocamentos produzidos na história e o modo como as dicotomias instruído $x$ educado, herege $x$ cristão, bárbaro x civilizado caminham em direção às oposições ignorante $x$ educado, analfabeto $x$ alfabetizado, 
enquadrando sujeitos e sentidos na objetividade, cientificidade e universalidade dominantes.

Ao tomar como referente a literatura e cultura europeia, "a alteridade presente na leitura e na escrita do passado ilumina e ofusca o dizer" (SILVA, 2015, p. 199), fazendo com que o memorável seja apenas o do mundo da escrita e de uma língua globalizante, deixando aos restos o lugar de sujeito falante de variantes linguísticas, e que desconsidera toda "base material da constituição da leitura e de seus efeitos estéticos [que se dá] em um espaço de conflitos e confrontos entre línguas, que se realizam na escolarização sob a forma da divisão" (p. 201).

Já na história da escolarização, contada por Serafim Leite em História da Companhia de Jesus, Silva (2015) destaca que o objeto da prática pedagógica não era o conhecimento sobre a língua ou as línguas, antes, o que se colocava era a conversão para transformar índios em civilizados, cristãos. Buscando nas diferenças entre o que se ensinava nas escolas de ler, escrever e contar e os colégios de formação secundária, a autora nos mostra como estes eram o prolongamento daquelas - em que o objetivo da primeira era "ganhar a infância" e do segundo "recrutar elementos para a Ordem" -, fazendo com que a formação constituísse uma elite com seu gosto pela retórica, pelo bem dizer, pelos torneios literários. Além disso, mostra também de que modo a língua geral era um instrumento importante para se chegar ao fim almejado. Nos recortes discursivos, o caráter espetacular, festivo das escolas da Companhia evidencia como os jesuítas ganhavam a alma do gentio com cantos, danças, festas, ao mesmo tempo em que usavam outros meios para doutrinar, recorrendo a castigo e disciplina. Significando o índio que não se submetia como melindroso, ressentido e mimado, o discurso nesse ponto aponta para "memórias antagônicas e de defesa de um sistema de organização social diferente do europeu letrado e cristão-católico" (idem, p. 215), em cuja diferença vemos o trabalho da contradição. $\mathrm{O}$ indígena resistia. Contudo, para ser possuidor da escrita, era necessário não ser índio, não ter os costumes e práticas selvagens, e ia-se à escola para ser humanizado, civilizado e salvo. "Cria-se, então, uma posição de sujeito da escolarização [...] que só se realiza na divisão entre o que foi - e deve ser negado - e o que será - que lhe é estranho e violento" (idem, p. 217).

Outro ponto de destaque da análise nessa obra de Serafim Leite é a questão da língua tupi como condição necessária para o ensino-conversão, ponto fundamental para a propagação e circulação dessa língua - ainda que não legitimada, mas gramatizada pelos jesuítas - tornando-se um "elemento de relação até entre índios, e não só entre os colonizadores e os indígenas" (p. 218). Por fim, ressalta Silva (2015) que Serafim Leite traz elementos para se pensar as articulações entre as trocas e práticas linguísticas e pedagógicas "como forma de atingir sua finalidade precípua: a colonização pela catequese sob o domínio da escrita ocidental" (idem, p. 220).

Finalizando o capítulo segundo de História da Alfabetização, Silva (2015) vai buscar os discursos que constituirão um gesto outro de leitura sobre a formação social e cultural do Brasil, diferente daqueles apresentados até aqui, pertencentes a outro campo do conhecimento: o da Sociologia. Começando com a obra de Gilberto Freyre, Casa Grande \& Senzala: formação da família brasileira sob o regime da economia patriarcal, a autora vai mostrar, pela análise do discurso freyriano, que a família patriarcal é considerada uma unidade colonizadora por excelência. Partindo de um outro lugar de 
interpretação, as práticas linguísticas e pedagógicas das mulheres e das crianças desse período, relatadas pela sociologia freyriana, constituem possibilidades de outros sentidos para escolarização e sujeitos, tornando possível pensar um movimento que constrói as identidades. No que se refere às crianças, destaca que foi "a criança" da senzala e da casa grande o outro de nossa história, "foco da catequese-ensino-conversão", quem apontou para uma relação em que se harmonizam e se apagam as diferenças, ainda que imaginariamente. Diante da aprendizagem, não apenas da leitura e da escrita, os sentidos não eram apenas os esperados pela catequese e por movimentos de resistência: "produziam relações novas, identidades outras" (SILVA, 2015, p. 231). Por meio da relação de ensino-aprendizagem com professores negros, doces e bons, em contraponto com o ensino nas escolas de padres, nas contações de histórias de amas e mucamas, a língua foi se constituindo numa "relação sacralizada, assimétrica entre interlocutores", entre o sagrado e o profano. A partir dos relatos de Freyre, Silva observa como se dá "a construção de nossa língua nacional" por um "processo civilizador em que a uniformização linguística se dava em condições próprias de aprendizagem, sem a qual a prática de uma língua comum não é possível” (SILVA, 2015, p. 233).

Observa ainda a autora que a escrita estava a serviço de uma assepsia do corpo e controle do prazer por meio da associação que faz Freyre entre "libertinagem-Deuslivros", na qual este último termo, os livros, é o caminho certo para se evitar o primeiro, a libertinagem. Para tanto, era necessário que "a leitura significasse soletração e a escrita, cópia”, a fim de domesticar o corpo e a alma (idem, p. 234).

Fechando o capítulo com a análise do texto de Florestan Fernandes, Antecedentes indígenas: organização social das tribos tupis, Silva (2015) evidencia de que modo há um corte com as formações discursivas apresentadas nos textos anteriores, por meio de uma relação entre essas formações - heterogêneas e não-lineares - que sustentou a produção de um processo de significação diferente pelo discurso de Fernandes (1989). Ali se encontram filiações discursivas aos sentidos de "coragem e heroísmo" para o sujeito indígena que faz com que discrepâncias e assimetrias reapareçam. Ancorando-se no que Orlandi (1998) traz sobre a questão da ética linguística, e da ética em se produzir ciência, Silva apresenta as diferentes formações discursivas - não como dado qualitativo, mas pensando na resistência de uma forma-sujeito que tem sua posição determinada por elas. A análise do texto de Fernandes aponta ainda para uma política de destribalização no sistema organizatório das tribos, que promoveu tanto "desequilíbrios insanáveis" quanto toda a política de assimilação dos indígenas à civilização cristã, pelo caminho da escolarização, gramatização, do ensino-conversão.

No terceiro e último capítulo, os discursos sobre um passado, retomados por Silva (2015), trazem a memória do dizer, um imaginário que põe em movimento a história e que está na base da compreensão de um objeto simbólico e histórico: a escrita alfabética. Sem ela não seria possível a construção de uma língua nacional e de um sistema de ensino dual e determinado pela historicidade, por esse passado. Nas palavras da autora: "temos, na verdade, sempre, um longo passado pela frente" (p. 253), um passado que significa e determina sujeitos e sentidos.

Ao discutir a constituição da escrita alfabética, da alfabetização na relação com a alteridade e em "espaços com fronteiras móveis em que o simbólico e o político se articulam" (p. 267), a autora traz a questão da ambiguidade fundamental (PÊCHEUX, 
2010, p. 54), presente nas formas dicotômicas que consideram a escrita como cópia, reprodução versus (re)criação, e "o caminho da abstração", apresentados nos discursos de Ferreiro (1993) e Vigotski (1996). Essas formas, para Silva (2015), trabalham os acontecimentos discursivos pelo jogo da identidade e da diferença, cuja ambiguidade também está presente na oposição língua oral x língua escrita, que deve ser pensada na relação com uma tecnologia de linguagem e uma língua gramatizada pelos jesuítas (a língua geral, a mais falada no Brasil por mais de 200 anos). Tal processo constituído pela e na contradição, não pode ser tratado como fracasso escolar, como nos diz Orlandi (2001), mas antes é o lugar onde "a ação inovadora, teórica e prática, terá de atuar", pois, é assim que a linguagem se torna conhecimento e "transforma o saber-fazer da oralidade em técnica verbalizada" (SILVA, 2015, p. 273), pensando a relação "língua-sujeitohistória nos espaços brancos existentes entre as palavras na escrita” (p. 278).

Em sua leitura dos textos dos séculos XVI-XVII - textos de Pero Vaz de Caminha: A carta; Manoel da Nóbrega: Cartas do Brasil; José de Anchieta: Cartas, informações, fragmentos históricos e sermões (1554-1594); André Thevet: As singularidades da França Antártica; Pêro Magalhães de Gândavo: Tratado da Província do Brasil; Frei Vicente do Salvador: História do Brasil: 1500-1627; Antônio Vieira: Sermão do Espírito Santo -, Silva (2015) retoma as questões trazidas nos capítulos precedentes, reafirmando o funcionamento da metáfora do sujeito como papel branco para compreender a filiação dos discursos e dos efeitos de sentidos produzidos para alfabetização, escolarização. Além disso, a autora também traz o trabalho de análise que Nunes (1996) faz do discurso lexicográfico do período colonial para pensar a rede discursiva que se constituiu no Brasil, refletindo sobre o dicionário como instrumento linguístico e "lugar privilegiado para marcar e demarcar limites e territórios do dizer" (SILVA, 2015, p. 407).

Pelo que conclui a autora de História da Alfabetização, o projeto político de cristianização-colonização, presente nesses discursos, elegeu dois espaços de ação: a escola e a língua. E, neles, a alfabetização não pode ser pensada como uma técnica, mas deve ser vista como um processo histórico-social, uma prática linguística, social e política, na qual a contradição diz respeito a um sujeito que deve se submeter ao significante em sua forma material, mas também, e ao mesmo tempo, a uma língua nacional una, dividida e distribuída desigualmente. Nesse espaço é "que o sujeito deverá se constituir como senhor de um dizer sempre-já-dividido" (SILVA, 2015, p. 416), sendo, portanto, a escrita alfabética um lugar instituinte de uma função discursiva do sujeito: a de autor. Entre o mundo não feito em alfabeto e o mundo feito em alfabeto (idem, p. 320), que o sujeito tenha o direto à diferença.

Ao revisitar sua tese, sem invalidar o que foi dito, muito menos para atualizar ou justificar interpretações já feitas, como afirma, Silva (2015) faz importante reestruturação do texto inicial, expondo o conhecimento acumulado ao longo dos anos numa obra-prima produzida por uma analista que acompanha toda consolidação da teoria da Análise de Discurso no Brasil e do projeto História das Ideias Linguísticas, que é parte constitutiva desse percurso, que nos traz "cousas memoráveis", que nos "entram pelos olhos e pelo coração". 


\section{Referências bibliográficas}

ORLANDI, E. Discurso e texto: formulação e circulação dos sentidos. Campinas, Pontes, 2001.

Ética e política linguística. Línguas e Instrumentos Linguísticos, n. 1, Campinas, Pontes, jan./jun., p. 7-16, 1998.

PÊCHEUX, M. Semântica e discurso. Uma crítica à afirmação do óbvio. Trad. Bras. Campinas: Editora da Unicamp, 2014.

Ler o arquivo hoje. Trad. Bras. Em: ORLANDI, E. (Orga.). Gestos de Leitura.

$3^{\text {a }}$. ed. Campinas: Editora da Unicamp, 2010.

O discurso: estrutura ou acontecimento. Trad. Bras. Campinas: Pontes, 1990.

$$
* * *
$$

Texto recebido em: agosto de 2016.

Aprovado e revisado em: agosto de 2016.

Publicado em: agosto de 2016

\section{Para citar este texto:}

COELHO, Cidarley Grecco Fernandes. O direito à diferença em um mundo feito em alfabeto. Entremeios [Revista de Estudos do Discurso], Seção Resenha, Programa de Pós-graduação em Ciências da Linguagem (PPGCL), Universidade do Vale do Sapucaí, Pouso Alegre (MG), vol. 13, p. 311-317, jul. - dez. 2016. (Resenha de SILVA, Mariza Vieira da. História da Alfabetização no Brasil: sentidos e sujeitos da escolarização. Campinas, SP: Editora da Unicamp, 2015. 432p. (Col. A Espessura da Linguagem, v.1)) DOI: http://dx.doi.org/10.20337/ISSN2179-3514revistaENTREMEIOSvol13pagina311a317 